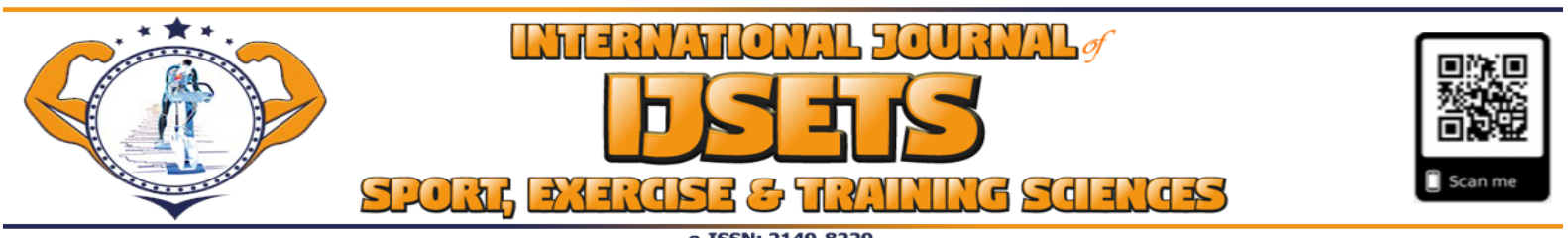

\title{
Effect of BMI on Fundamental Motor Skill Proficiency Among 9 to 10 years-old Turkish Children
}

\author{
Fatma lker KERKEZ1, Varol TUTAL ${ }^{2}$
}

\begin{tabular}{|c|c|}
\hline Abstract & Keywords \\
\hline $\begin{array}{l}\text { Aim: To examine the effect of body mass index (BMI) on Fundamental Motor Skill Proficiency } \\
\text { among } 9 \text { to } 10 \text { years-old Turkish children. }\end{array}$ & $\begin{array}{r}\text { Motor Skill Proficiency, } \\
\text { BMI, }\end{array}$ \\
\hline Methods: A total of 214 children (mean age $9.45 \pm 0.49$ ) were included in the study ( 110 girls, & 9-10 years-old, \\
\hline 104 boys). Fundamental Motor Skill Proficiency was assessed with the Test of Gross Motor & children. \\
\hline pment-Second Edition (TGMD-2). Body mass index (BMI) was calculated according to & \\
\hline the formula $[\mathrm{kg} /$ height 2$]$ after the height and weight measurement for each child and classified & \\
\hline & \\
\hline $\begin{array}{l}\text { n have a healthy weight, } 14.5 \% \text { were overweight and } 13.6 \% \text { were } \\
\text { ight and obese is higher for boys than for girls. There was a }\end{array}$ & \\
\hline en BMI groups in terms of TGMD-2 locomotor subtest scores ( $p$ & Article Info \\
\hline$<0.05)$, & Received: 26.10 .2020 \\
\hline iildren but does not affect obj & Accepted: 14.12 .2020 \\
\hline $\begin{array}{l}\text { doing the mostly static position. } \\
\text { Conclusion: This study demonstrates inadequate fundamental motor skills proficiency levels } \\
\text { among Turkish } 9-10 \text { vears old children. Childhood education centers should provide 'planned' }\end{array}$ & Online Published: 15.12 .2020 \\
\hline movement programs under the supervision of physical education teachers in order to support & DOI: $10.18826 /$ useeabd. 816482 \\
\hline
\end{tabular}

\section{INTRODUCTION}

Fundamental motor skills are common motor activities with specific observable models. Most skills used in sports, dance, physical fitness, and other movement activities are advanced versions of fundamental motor skills. For example, handball, tennis service or javelin throws are the advanced forms of basic overhand throwing (Gallahue et al., 2012). The fundamental motor skills are classified according to their functions as stability (non-locomotor), movement (locomotor) and object control skills (manipulative). The main factors affecting the acquisition of fundamental motor skills are the characteristics of the child (age, physical characteristics, gender, ability, interest, motivation), environmental factors (family, friends, living environment, economic status, etc.) and the requirements of the task. Although children have the potential to specialize in most FMSs until the age of 6 . The development rate is highly individual and depends on practice opportunities (Gallahue et al., 2012). In the literature, it is stated that physical activity opportunities are not sufficiently provided for the development of fundamental motor skills in children (Stodden et al., 2008; Whitehead, 2010).

The situation is not different in Turkey. Preschool education is not compulsory in Turkey. The preschool curriculum published by the Ministry of Education (2019) has motor development achievements, which are movement (changing position), stability movements, object control movements, movements that require the use of small muscles, and movements accompanied by music and rhythm. In the program, it is stated that the movement activity can be used to support the motor development of the children and to gain the movement skills as well as a transition activity, and also that the activities should last at least 30 minutes (the first 5 minutes being warming up games, 20 minutes of repetition of previous activity and new fundamental movement skills and last 5 minutes being cooling activities) and could take place in the classroom or outdoors in the yard. As can be seen, the program fails to meet the recommended physical activity level by the World Health Organization (2011) for the 5 to 17 age group both in theory and in practice: the WHO recommends at least 60 minutes of moderate to severe daily aerobic physical activity for this age group. In the elementary schools, the name of the

The role and contributions of each authors as in the section of IJSETS Writing Rules "Criteria for Authorship" is reported that: 1. Author: The study designing; collecting, analyzing and interpretation data and manuscript preparation, 2. Author: The study designing; collecting, analyzing and interpretation data and manuscript preparation.

${ }^{1}$ Corresponding author: Faculty of Sports Sciences, Muğla Sitk1 Koçman University, Muğla/Turkey, fatmakerkez@mu.edu.tr ORCID ID:0000-0002-5485-1834 ${ }^{2}$ Faculty of Sports Sciences, Siirt University, Siirt/Turkey, v.tutal@siirt.edu.tr, ORCID ID: 0000-0001-5647-9370 
class, which was "Game and Physical Activities" until 2018, has been changed to "Physical Education and Game" and it is taught by the classroom teacher 5 hours per week for 1st, 2nd, and 3rd graders and 2 hours per week for 4th graders. However, there are findings suggest that the classroom teachers use the play and physical education classes in order to make up for other classes, that teachers are not supported by school administrations in terms of materials and location, and that it would be beneficial to have physical education teachers to teach play and physical activities classes starting from the 1st grade (Guven \& Yildiz, 2014).

The effect of insufficient practice opportunities on the fundamental motor skills development among Turkish children has not been examined in depth. However, there are few studies examining motor development in general (Boz \& Gungor Aytar, 2012; Ersoz, 2012; Ulutas et al., 2017).

According to the OECD report (2016) on obesity rates among Turkish adults $28.8 \%$ of are obese. Obesity continues to increase despite the efforts of the Turkish Ministry of Health's Healthy Nutrition and Active Life Program since 2013. "Promoting Physical Activity 2015-2018" project, one of the projects implemented for this purpose, delivered one million bicycles to schools, universities and municipalities within 4 years. However, how much these bicycles were used or their impact are yet to be determined. According to Turkey Nutrition and Health Research (2014) study among children, 8.2\% of 6 to 18 year-old children were obese/overweight (M:9.1\%, F:7.3) 14.3\% were slightly overweight (M: 14.2 F: 14.4), 14.9\% were thin (M:15.2, F:14.5), and 3.9\% were very thin (M: 3.8, F: 4.1). However, there is no study examining the relationship between BMI and fundamental motor development.

The aim of this study was to determine the fundamental motor skill levels of Turkish children aged 9 to 10 according to their BMI groups and to examine their fundamental skill levels according to age and gender variables with identifying the association between the BMI and the gross motor skill.

\section{METHOD}

\section{Participants}

Participants of the study were 214 healthy children (110 girls, 104 boys) aged 9 to 10 years (mean age $9.45 \pm 0.49$ years) who reside in the city center of Malatya province in Turkey. Schools that were recruited were from various socioeconomic backgrounds. According to Ministiry of Education 20122013 statistics, there was 56.221 primary school students in Malatya. In order to represent the universe, an average of 400 students were determined as a sample on a voluntary basis and randomly, taking into account $5 \%$ sampling error. In addition to the Ethics Committee approval that was obtained from the Inonu University (2013-152), consent forms were also obtained from parent and children for the study. 258 of 400 families whose consent forms were sent agreed to participate in the study, 214 children were reached on the days of measurement.

\section{Measurement Procedures}

Height measurement: Height was measured barefoot with an accuracy of $0.1 \mathrm{~cm}$, using a standard steel stadiometer.

Weight measurement: Weight was measured barefoot with no metal on the Tanita BC-418 Segmental Body Analysis System (Tanita Corporation, Tokyo, Japan).

BMI: BMI values were calculated taking CDC 2-20 age growth curve table by using the BMC Percentile Calculation tool for children and adolescents (3): $<5$ percentile as thin, 5-85. percentile as healthy weight, 85-95 percentile as overweight, and the $>95$ as obese.

\section{Evaluation of Fundamental Motor Skill Level}

In this study, fundamental motor skill level was evaluated through TGMD-2 test. TGMD-2 was developed by Ulrich (2000) to evaluate the fundamental motor development of children between the ages of 3-10, depending on age. TGMD- 2 is a motor assessment tool that requires the observation of 12 motor skills consisting of two subtests: locomotor subtests (running, jumping, galop, jumping, hopscotch and gliding) and object control subtests (catching, kicking ball, ball bumping, overhand ball throwing and rounding ball under hand and batting with two hands). Each skill is evaluated according to three to five performance criteria. If a participant demonstrates the criteria, he / she receives a 1 , if not a 0 . It includes the total raw score ( $0-48$ points) of the observed criteria for each subscale. Raw scores can be converted to percentiles and standard scores, which allows comparison with the scores of their peers. 


\section{Process}

All measurements were carried out in the school gyms under the supervision of teachers. First, height and weight were measured and then locomotor and manipulative tests were recorded on video. After that, two different experts watched the video recordings and made TGMD-2 test evaluations and prepared averages.

\section{Statistical analysis}

SPSS 22 package program was used for data analysis and statistical significance was determined as 0.05 . The normality test by Shapiro Wilk was used to verify the data distribution. In order to compare fundamental motor skill raw scores according to age and gender using average and percentile value descriptive statistical method, the study used t-test for independent groups and one-way Anova test to compare according to BMI groups. The association between the BMI and the gross motor skill was analyzed through the Pearson bivariate correlation (rs) overall and by subtests.

\section{RESULTS}

\section{Weight, Height, and Body Mass Index}

$72 \%$ of the children had a healthy weight $(\mathrm{M}=28.8 \mathrm{~kg}$; $\mathrm{BMI}=16.1) ; 14.5 \%$ were overweight $(\mathrm{M}=39.7$ $\mathrm{kg}$ : $\mathrm{BMI}=20.3)$; and $13.6 \%$ were obese $(\mathrm{M}=46.7 \mathrm{~kg}$; $\mathrm{BMI}=24.3)$.

In terms of age groups, 9.3\% of 9-year-old children were overweight and $16.9 \%$ were obese. Whereas for 10 -year old children, $20.8 \%$ of them were overweight and $9.4 \%$ were obese. The ratio of overweight and obese boys was found to be higher than that of girls. Children's height, weight, and BMI information were categorized according to their age and gender and are presented in Table 1.

Table 1. Descriptive information for boys and girls aged 9-10 years.

\begin{tabular}{|c|c|c|c|c|c|c|}
\hline \multirow{2}{*}{$\begin{array}{c}\text { Gender } \\
\text { Age Group }\end{array}$} & \multicolumn{3}{|c|}{ Girl $(n=110)$} & \multicolumn{3}{|c|}{ Boy $(n=104)$} \\
\hline & $\begin{array}{c}9 \text { years-old } \\
(n=69)\end{array}$ & $\begin{array}{c}10 \text { years-old } \\
(n=41)\end{array}$ & Avg. & $\begin{array}{c}9 \text { years-old } \\
(n=49)\end{array}$ & $\begin{array}{c}10 \text { years-old } \\
(n=55)\end{array}$ & Avg. \\
\hline Variables & $\overline{\mathbf{X}} \pm \mathbf{S D}$ & $\overline{\mathbf{X}} \pm \mathbf{S D}$ & $\overline{\mathbf{X}} \pm \mathbf{S D}$ & $\overline{\mathbf{X}} \pm \mathbf{S D}$ & $\overline{\mathbf{X}} \pm \mathbf{S D}$ & $\overline{\overline{\mathbf{X}} \pm \mathbf{S D}}$ \\
\hline Height (cm) & $133.3 \pm 6.3$ & $136.4 \pm 6.6$ & $134.5 \pm 6.6$ & $133.2 \pm 6.2$ & $137.5 \pm 6.8$ & $135.5 \pm 6.8$ \\
\hline Weight (kg) & $31.3 \pm 7.4$ & $32.4 \pm 5.7$ & $31.7 \pm 6.8$ & $33.3 \pm 8.5$ & $34.5 \pm 8.9$ & $33.9 \pm 8.7$ \\
\hline BMI & $17.4 \pm 3.1$ & $17.3 \pm 2.3$ & $17.4 \pm 2.8$ & $18.6 \pm 3.6$ & $18.0 \pm 3.5$ & $18.3 \pm 3.6$ \\
\hline & n (\%) & n (\%) & Total n (\%) & n (\%) & n (\%) & Total n (\%) \\
\hline Healthy Weight & $55(50.0)$ & $30(27.3)$ & $85(77.3)$ & $32(30.8)$ & $37(35.6)$ & $69(66.3)$ \\
\hline Overweight & $5(4.5)$ & $9(8.2)$ & $14(12.7)$ & $6(5.8)$ & $11(10.6)$ & $17(16.3)$ \\
\hline Obese & $9(8.2)$ & $2(1.8)$ & $11(10.0)$ & $11(10.6)$ & $7(6.7)$ & $18(17.3)$ \\
\hline
\end{tabular}

\section{Fundamental Motor Skill Level}

\section{BMI- Fundamental Motor Skill Proficiency}

Pearson's bivariate correlational results indicate that BMI showed negative correlation with FMS total $(\mathrm{r}=-0.22, \mathrm{p}<0.001)$ and locomotor subtest total $(\mathrm{r}=-0.24 . \mathrm{p}<0.001)$, but the relationship between manipulative subtest and total score was not significant.

When locomotor subtest raw score was compared using one-way analysis of variance, a significant difference was found among the groups of healthy weight, overweight and obese children $[\mathrm{F}(6.348)=$ 91.80, $\mathrm{p}=0.02]$. According to the post hoc test result, the locomotor subtest raw score of obese children was significantly lower than that of children with healthy weight. Manipulative subtest total score difference according to BMI groups was not significant $[\mathrm{F}(2.615)=68.55 . \mathrm{p}=0.076]$. Gross motor test total score was significantly different among BMI groups $[\mathrm{F}(6.990)=317.69, \mathrm{p}=0.01]$. The scores of healthy children were significantly higher than those of obese children. 


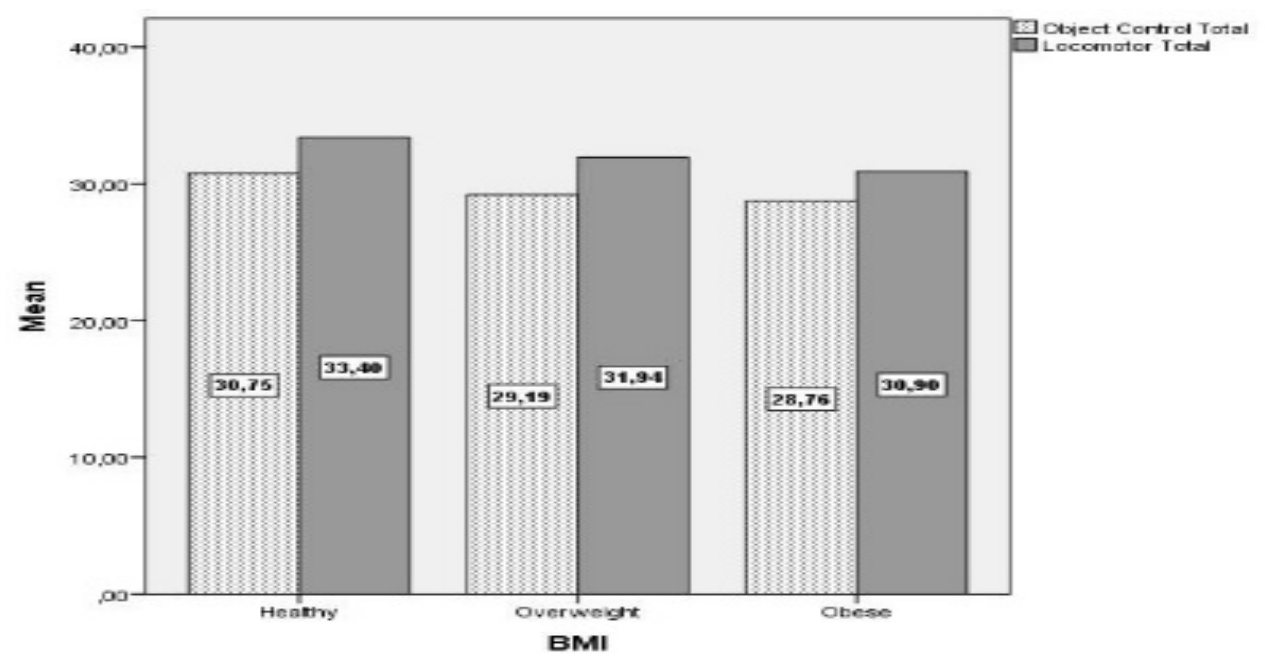

Figure 1. Locomotor and manipulative test raw scores by BMI groups.

\section{Age and Gender - Fundamental Motor Skill Proficiency}

Locomotor test total score of 10-year-old children (34.2 \pm 4.8$)$ was significantly higher than that of (31.7 \pm 3.4$)$ 9-year-old children $(\mathrm{t}=-5.040, \mathrm{p}<0.01)$. The total score of manipulative subtest of the 10 yearold children $(32.4 \pm 4.8)$ was significantly higher than the 9 year-old children $(28.4 \pm 4.7)(t=-6.036 . p$ $<0.01)$.

There was no significant difference between boys' (33.0 44.4$)$ and girls' (32.6 \pm 3.3$)$ locomotor subtest scores $(t=0.826 . p>0.05)$. There was a significant difference in the total score of the manipulative subtest $(t=9.911, p<0.01)$ between boys $(33.2 \pm 4.5)$ and girls $(27.4 \pm 3.9)$. The fundamental motor skill levels were categorized according to age and gender and are presented in Table 2.

Table 2. Descriptive information on fundamental motor skill levels.

\begin{tabular}{|c|c|c|c|c|c|c|}
\hline Gender & \multicolumn{3}{|c|}{ Girls (n=110) } & \multicolumn{3}{|c|}{ Boys $(n=104)$} \\
\hline Age Group & $\begin{array}{c}9 \text { years-old } \\
(n=69)\end{array}$ & $\begin{array}{c}10 \text { years-old } \\
(\mathrm{n}=41)\end{array}$ & Avg. & $\begin{array}{c}9 \text { years-old } \\
(\mathrm{n}=49)\end{array}$ & $\begin{array}{c}10 \text { years-old } \\
(\mathrm{n}=55)\end{array}$ & Avg. \\
\hline $\begin{array}{c}\text { Locomotor and Object } \\
\text { control test scores * }\end{array}$ & $\overline{\mathbf{X}} \pm \mathbf{S D}$ & $\overline{\mathbf{X}} \pm \mathbf{S D}$ & $\overline{\mathbf{X}} \pm \mathbf{S D}$ & $\overline{\mathbf{X}} \pm \mathbf{S D}$ & $\overline{\mathbf{X}} \pm \mathbf{S D}$ & $\overline{\mathbf{X}} \pm \mathbf{S D}$ \\
\hline Locomotor, total score & $31.6 \pm 2.7$ & $34.2 \pm 3.5$ & $32.6 \pm 3.3$ & $31.7 \pm 4.2$ & $34.2 \pm 4.2$ & $33.0 \pm 4.4$ \\
\hline Running & $6.2 \pm 0.9$ & $6.4 \pm 0.7$ & $6.3 \pm 0.8$ & $6.6 \pm 1.1$ & $6.9 \pm 0.9$ & $6.7 \pm 1.1$ \\
\hline Hopping & $5.3 \pm 1.1$ & $5.8 \pm 1.3$ & $5.5 \pm 1.2$ & $4.9 \pm 1.1$ & $5.5 \pm 1.0$ & $5.2 \pm 1.1$ \\
\hline Galloping & $4.8 \pm 1.3$ & $5.7 \pm 1.4$ & $5.1 \pm 1.4$ & $4.4 \pm 1.2$ & $4.9 \pm 1.4$ & $4.7 \pm 1.3$ \\
\hline Slide & $5.2 \pm 0.8$ & $5.6 \pm 0.8$ & $5.4 \pm 0.8$ & $5.2 \pm 1.1$ & $5.8 \pm 0.9$ & $5.6 \pm 1.1$ \\
\hline Leap & $4.4 \pm 0.6$ & $5.0 \pm 0.8$ & $4.6 \pm 0.7$ & $4.3 \pm .08$ & $4.8 \pm 1.0$ & $4.6 \pm 0.9$ \\
\hline Horizontal jumping & $5.6 \pm 0.9$ & $5.5 \pm 1.1$ & $5.6 \pm 1.0$ & $6.0 \pm 1.1$ & $6.1 \pm 1.5$ & $6.0 \pm 1.3$ \\
\hline Object control, total score & $26.2 \pm 3.5$ & $29.5 \pm 3.7$ & $27.4 \pm 3.9$ & $31.6 \pm 4.2$ & $34.6 \pm 4.4$ & $33.2 \pm 4.5$ \\
\hline Striking a stationary ball & $2.4 \pm 1.0$ & $2.5 \pm 1.1$ & $2.4 \pm 1.0$ & $3.2 \pm 1.3$ & $3.3 \pm 1.4$ & $3.2 \pm 1.4$ \\
\hline Kick & $4.0 \pm 1.1$ & $4.7 \pm 1.5$ & $4.2 \pm 1.3$ & $5.6 \pm 1.0$ & $6.6 \pm 1.3$ & $6.1 \pm 1.3$ \\
\hline Overhand throw & $3.7 \pm 1.9$ & $4.9 \pm 1.4$ & $4.2 \pm 1.8$ & $5.0 \pm 2.0$ & $6.3 \pm 1.2$ & $5.7 \pm 1.7$ \\
\hline Catch & $4.7 \pm 1.2$ & $5.0 \pm 1.2$ & $4.8 \pm 1.2$ & $5.2 \pm 1.0$ & $5.3 \pm 1.1$ & $5.0 \pm 1.2$ \\
\hline Stationary dribble & $5.1 \pm 1.5$ & $6.0 \pm 1.6$ & $5.4 \pm 1.6$ & $6.1 \pm 1.3$ & $6.5 \pm 1.3$ & $6.3 \pm 1.3$ \\
\hline Underhand roll & $6.0 \pm 1.3$ & $6.2 \pm 1.5$ & $6.1 \pm 1.4$ & $6.3 \pm 1.3$ & $6.9 \pm 1.2$ & $6.6 \pm 1.3$ \\
\hline
\end{tabular}

\section{DISCUSSION}

The prevalence of obesity in children is increasing. The negative impact of obesity on health was described in detail for many years. Although the effect of obesity on mobility of children has been studied in the international literature for over 30 years, there is no data on the effect of being overweight and obese on motor efficacy of Turkish children. This study is the first one examining the FMS levels 
of 9 to 10 -year-old Turkish children according to BMI groups. The study included 214 children with an average age of $9.45 \pm 0.49$ years and evaluated FMS results according to age and gender.

FMS results in Turkish children were compared with similar studies using TGMD-2 test. The locomotor and object control raw scores of Turkish children were found to be lower than the results by Ré et al. (2018), which for the girls with same age were $35.8 \pm 4.3$ for locomotor total and $28.8 \pm 5.1$ for object control and for boys' locomotor total was $35.9 \pm 4.3$ and object control total was $33.0 \pm 5.7$. On the other hand, it was found to be higher than the result by Nobre et al. (2016) who found that total locomotor in girls of the same age was 25.5 and object control was 26 and locomotor total for boys was 25.1 and object control total was 26.3. When the results were compared with the subtest scores given in Nobre et al. (2016) individually, it showed that the lowest score of the Turkish children was for 'striking a stationary ball test', which was one of the object control subtests $(2.4 \pm 1.0$ for girls and $3.2 \pm 1.4$ for boys). The failure of this subtest stems from the fact that Turkish children had never learned this skill before since 'striking a stationary ball' was not included in any street game or in the school curriculum. On the other hand, hitting, catching, dribbling can be practiced to a certain extent in children's games and in the "Physical Education and Game" classes in primary schools.

In the literature, there are different results about the relationship between BMI and motor skill level. There are few studies showing that there is no relationship between BMI and fundamental motor skill level and these studies include preschool population. Catenassi et al. (2007) found no relation between BMI and motor skills of 4 to 6 year-old children. Likewise, Lin \& Yang (2015) reported that the effect of BMI on locomotor, object control and fundamental motor skill levels of children aged 3 to 7 year-old was very limited.

On the other hand, there are more studies showing that being overweight and obese negatively affects mobility of children (Saygin \& Ceylan, 2017; Poulsen et al., 2015; Cliff et al., 2012; Lopes et al., 2012; D'hondt et al., 2009; Wearing et al., 2006).

Marmeleira et al. (2017) noted that motor competence of children aged 6 to 10 year-old was negatively associated with body fat and that children with healthy weight displayed better motor competence than those who were overweight or obese. The results that suggested that the negative impact of excessive body weight was stronger for locomotor skills including dynamic body movements than object control skills in steady state and that fine motor skills were comparatively independent of limitations caused by excess body weight were similar to the results of our study. In their study investigating the relationship between motor skills and BMI in children aged 5 to 10 years, D'Hondt et al. (2009) noted that obese children had lower levels of motor skills than their healthy and overweight peers. Southall, Okely \& Steele (2004) reported that the real and perceived physical competence of overweight children in the sample with an average age of 10.8 years was lower than those with a healthy weight. Our results show that the situation is similar for Turkish children. Obese children had lower results than healthy children in locomotor subtests requiring mobility. The limitation of this study is the low sample numbers and low number of overweight and obese children in the sample. The effect of excessive weight on mobility should be further explained with studies to be conducted with a larger sample group.

\section{CONCLUSION}

In conclusion, this study demonstrates inadequate fundamental motor skills proficiency levels among Turkish 9-10 years old children. Obese children had lower results than healthy children in locomotor subtests requiring mobility. It can be said that being overweight restricts mobility for Turkish children but does not affect object control skills that doing the mostly static position. If asked to train successful athletes in Turkey, motor development and nutrition in children cannot be left just to the attention of parents. There should be a strong government policy that supports children's participation in planned movement training from an early age under the supervision of physical education teachers.

\section{ACKNOWLEDGEMENTS}

The authors report no conflict of interest. A part of this study was presented at the V. INES Science Technolohy and Innovation Congress (STI 2019) 17 - 21 April 2019 as oral presentation. 


\section{REFERENCES}

Boz, M. \& Gungor Aytar, A. (2012). The Effect of Fundamental Movement Education on Pre-school Children's Movement Skills. Hacettepe University Journal of Education, Special Issue 1: 51-59.

Catenassi, F, Marques, Z.I., Bastos, C.B., Basso, L., Vaz Ronque, E.R. \& Gerage, A.M. (2007). Relationship between body mass index and gross motor skill in four to six-year-old children. Rev Bras Med Esporte, 13(4), 203-206. DOİ: 10.1590/S1517-86922007000400003.

CDC. (2019). BMI Percentile Calculator for Child and Teen, 2019. Retrieved from https://www.cdc.gov/healthyweight/bmi/calculator.html on 20 October 2019.

Cliff, D.P., Okely, A.D., Morgan, P.J., Jones, R.A., Steele, J.R. \& Baur, L.A. (2012). Proficiency deficiency: Mastery of fundamental movement skills and skill components in overweight and obese children. Obesity, 20, 1024-33. DOI: 10.3109/17477166.2011.575154.

D'hondt, E., Deforche, B., Bourdeaudhuij, I.D. \& Lenoir, M. (2009). Relationship Between Motor Skill and Body Mass Index in 5- to 10-Year-Old Children. Adapted Physical Activity Quarterly, 26, 2137. DOI: 10.1123/apaq.26.1.21.

Ersoz, Y. (2012). Effect of Multi-Skill Sport Education on Motor Development of Boys aged 7 to 10. Unpublished Sport Physiology Master's Thesis, Izmir, Turkey, Dokuz Eylül University.

Gallahue, D.I., Ozmun, J.C. \& Goodway, J.D. (2012). Understanding Motor Development: Infants, Children, Adolescents, Adults Motor (7th ed.). Boston, MA: McGraw-Hill.

Guven, O. \& Yildiz, O. (2014). Expectations of the Classroom Teachers from Play and Physical Activities Lesson. Kastamonu Education Journal, 22 (2), 525-538.

Lin, S-J. \& Yang, S-C. (2015). The Development of Fundamental Movement Skills by Children Aged Six to Nine. Universal Journal of Educational Research, 2015; 3(12): 1024-1027, DOI: 10.13189/ujer.2015.031211.

Lopes, V.P., Stodden. D.F., Bianchi. M.M., Maia. J.A. \& Rodrigues. L.P. (2012). Correlation between BMI and motor coordination in children. Journal of Science and Medicine in Sport, 2012; 15, 38 43. DOI: 10.1016/j.jsams.2011.07.005.

Marmeleira, J., Veiga. G., Cansado. H. \& Raimundo. A. (2017). Relationship between motor proficiency and body composition in 6- to 10-year-old children. Journal of Pediatrics and Child Health, 53, 348-353. DOI:10.1111/jpc.13446.

Nobre, G.C., Bandeira, P.F.R. \& Valentini, N.C. (2016). The Relationship Between General Perceived Motor Competence, Perceived Competence Relative to Motor Skill and Actual Motor Competence in Children. Journal of Physical Education, 27, e2744. DOI: 10.4025/jphyseduc.v27i1.2744.

OECD Obesity Update (2016). Retrieved from https://www.oecd.org/health/obesity-update.htm on 20 October 2020.

Poulsen, A.A., Desha, L., Ziviani, J., Griffiths, L., Heaslop, A., Khan, A. \& Leong, G.M. (2011). Fundamental movement skills and self-concept of children who are overweight. International Journal of Pediatric Obesity, 6, e464-71. DOI: 10.3109/17477166.2011.575143.

Ré, A.H.N., Logan, S.W., Cattuzzo, M.T., Henrique, R.S., Tudela, M.C. \& Stodden, D.F. (2018). Comparison of motor competence levels on two assessments across childhood. Journal of Sports Sciences, 36:1, 1-6, DOI:10.1080/02640414.2016.1276294.

Saygin, Ö., \& Ceylan, H. İ. (2017). A Comparison of body mass index and daily step numbers of secondary school and high school students according to age and gender. Int J Sport Exer \& Train Sci, 3 (4), 142-152. DOI: 10.18826/useeabd.337683

Southall, J., Okely, A. \& Steele, J. (2004). Actual and perceived physical competence in overweight and non-overweight children. Pediatric Exercise Science, 16, 15 - 24. DOI: 10.1123/pes.16.1.15.

Stodden, D.F., Goodway, J.D., Langendorfer, S.J., Roberton, M.A., Rudisill, M.E., Garcia, C. \& Garcia, L.E. (2008). A developmental perspective on the role of motor skill competence in physical activity: An emergent relationship. Quest, 60(2), 290-306. DOI: 10.1080/00336297.2008.10483582. 
The Preschool Curriculum. (2019). Ministry of Education, Ankara, Turkey, 2013. Retrieved from https://tegm.meb.gov.tr/dosya/okuloncesi/ooproram.pdf on 20 October 2019.

Turkey Nutrition and Health Research. (2014). Ministry of Health, Ankara, Turkey, 2014. Hyperlink: [https://hsgm.saglik.gov.tr/depo/birimler/saglikli-beslenme-hareketli-hayatdb/Yayinlar/kitaplar/diger-kitaplar/TBSA-Beslenme-Yayini.pdf]. Retrieved on 14 January 2020.

Ulrich, D. (2000). Test of gross motor development: second edition Austin, TX: PRO-ED.

Ulutas, A., Demir, E. \& Yayan, E.H. (2017). Effect of Motor Development Program on Rough and Fine Motor Development of Five-Six-Year-Old Children. Abant Izzet Baysal University Education Faculty Journal, 17 (3), 1523-1538.

Wearing, S.C., Hennig, E.M., Byrne, N.M., Steele, J.R. \& Hills, A.P. (2006). The impact of childhood obesity on musculoskeletal form. Obesity Reviews, 7: 209-18. DOİ:10.1111/j.1467789X.2006.00216.x.

Whitehead, M. (2010). Physical literacy: Throughout the life course, Oxon, MD: Routledge.

WHO. (2019). Global Recommendations on Physical Activity for Health, 5-17 years old, USA, 2011. Retrieved from https://www.who.int/dietphysicalactivity/factsheet_young_people/en/ 